\title{
Köpeklerdeki Uzun Kemiklerin Evrişimsel Sinir Ağları Kullanılarak Sınıflandırılması
}

\author{
Gülnur Begüm ERGÜN ${ }^{1 *}$, Selda GÜNEY ${ }^{2}$, Tahsin Gürkan ERGÜN ${ }^{3}$ \\ 1,2 Elektrik-Elektronik Mühendisliği, Mühendislik Fakültesi, Başkent Üniversitesi, Ankara, Türkiye \\ ${ }^{3}$ Cerrahi Anabilim Dalı, Veteriner Fakültesi, Ankara Üniversitesi, Ankara, Türkiye \\ *11 gbcangoz@baskent.edu.tr, ${ }^{2}$ seldaguney@ baskent.edu.tr, ${ }^{3}$ tahsingurkanergun@ gmail.com
}

\begin{abstract}
Öz: Son yılların en popüler konularından olan derin öğrenme, pek çok alanda olduğu gibi biyomedikal alanda da s1kça kullanılmaktadır. Çeşitli görüntüleme yöntemleri ile elde edilen görüntüler kullanılarak hastalık ve kırık tespiti, biyolojik veri kestirimi, doku ve organ bölütlemesi, eksik veri tamamlanması gibi nice uygulama derin öğrenme algoritmaları sayesinde başarılı bir şekilde gerçekleştirilmektedir. Ancak bahsi geçen uygulamaların çok büyük bir çoğunluğu beşeri hekimlikte yapılırken, veteriner tıp geri planda bırakılmıştır. Özellikle literatürde bu alandaki eksikliğin fark edilmesi bu çalışma konusunun en büyük motivasyon kaynağı olmuştur. Bu çalışmada, Ankara Büyükş̧ehir Belediyesi Sokak Hayvanları Geçici Bakım Evi'nden alınan, köpeklere ait röntgenleri içeren geniş kapsamlı bir veri seti, derin öğrenme algoritmaları ile işlenmiştir. Amaç, köpeklere ait X-Ray görüntülerinden uzun kemiğin çeşidinin belirlenmesidir. Biyomedikal görüntü işleme alandaki pek çok çalışma gibi, bu çalışmada da Evrişimsel Sinir Ağları (Convolutional Neural Network, CNN) mimarileri kullanılmıştır. AlexNet, GoogLeNet ve VGG-19 derin öğrenme modelleri ile öğrenme aktarımı gerçekleştirilmiş, destek vektör makineleri (Support Vector Machines, SVM) ile sinıflandırma performansı test edilmiştir.
\end{abstract}

Anahtar kelimeler: Derin öğrenme, evrişimli sinir ağları, görüntü işleme, uzun kemikler, sınıflandırma.

\section{Classification of the Long Bones in Dogs Using Convolutional Neural Network}

\begin{abstract}
Deep learning, one of the most popular topics of recent years, is frequently used in the biomedical field. Disease and fracture detection, data estimation, tissue and organ segmentation, and many other applications are successfully carried out with deep learning algorithms. However, while these applications are valid for human medicine, veterinary medicine is left behind. So, the deficiency in the literature about animal's X-Ray images processing has been the biggest motivation for this study. In this work, a comprehensive dataset containing dog X-Rays taken from Ankara Metropolitan Municipality Stray Animals Temporary Nursing Home, was processed with deep learning algorithms. It is aimed to determine the type of long bone. Like many other studies, Convolutional Neural Networks'(CNN) architectures are utilized in this study, too. Transfer learning was carried out with AlexNet, GoogLeNet and VGG-19 deep learning models, and the classification performance was tested with Support Vector Machines (SVM).
\end{abstract}

Key words: Deep learning, convolutional neural networks, image processing, long bones, classification.

\section{Giriş}

Son yıllarda teknolojinin gelişimine paralel olarak işlemci hızlarının artması, milyarlarca verinin çok kısa zamanlarda işlenmesine olanak tanımıştır. Bu teknolojik iyileşmeler ile literatürde derin öğrenme olgusu ortaya çıkmış, milyarlarca verinin işlenip aralarında anlamlı bir örüntü yakalanarak insanlığa faydalı çıktılar üretmesi amaçlanmıştır. Özellikle 2010 yıllarından sonra oldukça popüler hale gelen derin öğrenme algoritmalarının pek çok alanda uygulamaları bulunmaktadır [1]. Biyomedikal alana bakılacak olursa; manyetik rezonans (MR) ile tomografi görüntüleri kullanılarak hastalık ile kırık tespitinin, biyolojik veri kestiriminin, doku ve organ bölütlemesinin, eksik veri tamamlanmasının ve daha nice uygulamanın artık derin öğrenme algoritmaları sayesinde yüksek başarı oranları ile gerçekleştirildiği söylenebilir [2-5]. Ancak bahsi geçen uygulamaların neticesinde ulaşılan başarıların çok büyük bir çoğunluğu insandan alınan görüntülerle elde edilirken; hayvan anatomisinin derin öğrenme algoritmaları tarafından analizi, literatür taramasında tespit edilmemiştir. Oysaki insan vücudunda görülen hastalık ve yaralanmalara, hayvanlarda da rastlamak pek mümkündür. Hayvan sağlığı gerek evcil hayvan besleyen insanlar gerekse de gıda-taşımacılık vb. amaçlarla hayvan sahibi olan insanlar için göz ardı edilemeyecek bir önem arz etmektedir.

\footnotetext{
* Sorumlu yazar: gbcangoz@ baskent.edu.tr. Yazarların ORCID Numarası: ${ }^{1}$ 0000-0001-8469-5484, ${ }^{2}$ 0000-0002-0573-1326, ${ }^{3} 0000-0003-$ 0447-7677.
} 
İnsan tabanlı veri setleri ile biyomedikal görüntü işlemede genel amaç; sınıflandırma, algılama, veri tamamlama ve bölütleme olarak kategorize edilebilir. Bu amaçlı yapılan çalışmaların genelinde MR ve tomografi görüntüleri kullanılmışıı [3,5]. Özellikle kemiklerdeki kırıkların tespit edilmesi yine bu alanda en çok çalışılan konulardan birisidir [5-7]. İnsan kemiklerindeki kırıklarının varlığı neredeyse uzman bir ortopedist kadar derin öğrenme algoritmalarınca saptanabilmektedir [8,9]. Bu çalışmada, insan anatomisi üzerine yapılan çalışmaların hayvan anatomisine uygulanması ve sonuçlarının analiz edilmesi hedeflenmiştir.

Derin öğrenme algoritmaları, öğrenme aşamasında geleneksel makine öğrenmesi algoritmalarına oranla çok daha fazla veriye ihtiyaç duyarlar [10]. Veri sayısı, çeşitliliği ve verinin doğru ayrılmış olması bir algoritmanın başarını etkileyen en önemli faktörlerdendir. Bu da veri setinin olabildiğince çeşitli, güvenilir bir kaynak tarafindan etiketlendirilmiş ve verilere uygun algoritmalar tarafindan test edilmesi anlamına gelmektedir. Bu bağlamda, Ankara Büyükşehir Belediyesi Sokak Hayvanları Geçici Bakım Evi'nden alınan, köpeklere ait röntgenleri içeren geniş kapsamlı bir veri seti; alanınca uzman veteriner ortopedistimiz tarafindan uzun kemiklere göre etiketlendirilmiştir. Amaç, derin öğrenme algoritmaları ile köpeklere ait röntgen görüntülerinden uzun kemiğin çeşidini belirlemektir.

Bu alandaki pek çok çalışma gibi, bu çalışma da Evrişimsel Sinir Ağları (Convolutional Neural Network, CNN) kullanılarak denenmiştir [3,4,11,12]. Halihazırda birbirinden farklı birçok derin ağ mimarisi türetilmiş ve literatürde kabul görmüştür. Çalışma kapsamında da farklı derin ağ mimarileriyle en iyi sonuç elde edilmeye çalışılmıştır.

\section{Literatür Çalıșmaları}

Biyomedikal görüntü işleme, derin öğrenme algoritmalarının en büyük uygulama alanlarından birisidir. $\mathrm{Bu}$ sebeple literatüre kazandırılmış fazlaca çalışma mevcuttur; ancak bu mevcut çalışmaların çok büyük bir kesimi beşeri hekimlik üzerinedir $[5,6,7,9]$. Oysa veteriner tıp için de benzer çalışmaları yapmak mümkündür. Genel olarak beşeri hekimlikte yapılan bu çalışmalar; sınıflandırma, algılama, veri tamamlama ve bölütleme gayesiyle yapılmıştır. Görüntüleme yöntemleri sayesinde alınan görüntülere bakılarak, sınıflandırma işleminde genelde hastalık var veya yok tanısı koyma; algılama işleminde lezyonlu bir bölgeyi tespit etme ve/veya işaretleme; bölütleme işleminde ise dokuların ve/veya organların bölümlendirilmesi ile hacim ve şekilsel bilgilerine ulaşılması hedeflenir. Bu hedeflere ulaşmada en çok tercih edilen ağ yapısı CNN'dir.

Türkiye'de görüntü işleme adına yapılan doktora tezleri incelendiğinde neredeyse üretilen her iki tezden birinin biyomedikal alanda olduğu söylenebilir. YÖK Tez Merkezi’nden edinilen verilere göre; 2010-2020 yılları arasında görüntü işleme konusunda yazılan 60 doktora tezinden 24 tanesinin biyomedikal alanda olduğu tespit edilmiştir [13]. Ayrıca son yıllardaki literatür incelendiğinde ortopedi dalının yanında görüntü işleme konusunun göz hastalıkları, nöroloji, göğüs hastalıkları, dermatoloji, kardiyoloji gibi diğer tıp dallarında da uygulandığı görülmektedir [14-29].

Ortopedi alanında, daha çok kırık tespiti ve eklem-doku bölütleme işlemleri üzerinde durulmuştur. Örneğin çocuklardaki distal tibial kırıkların saptanmasında CNN yönteminin başarısı incelenmiştir. 980 görüntü, InceptionV3 mimarisinde işlenmiş ve \%95,9'luk bir performans yakalanmıştır [12].

Amacı menisküs yırtığı varlığına göre MR görüntülerini sınıflandırmak olan bir çalışmada R-CNN yöntemi ile \%90,6'lık başarı elde edildiği gözlenmiştir [20].

Farklı hastalardan alınan X-ray görüntüleri ile geniş kapsamlı bir veri seti, dört farklı denetimli/denetimsiz öğrenme metotlarıyla test edilmiştir: lojistik regresyon, L2 ceza parametresi ile lojistik regresyon, k-NN ve CNN. $\mathrm{Bu}$ araştırmada ilgi çeken noktalardan bir tanesi en yüksek başarının $\mathrm{CNN}$ yerine $\mathrm{k}-\mathrm{NN}$ algoritması ile elde edilmiş olmasidır [21].

Literatürde ender rastlanan hayvan görüntülerinin işlenmesine, domuzlar ile gerçekleştirilen bir çalışma örnek olarak verilebilir. Domuzların X-Ray görüntüleri ile iskelet yapıları CNN uygulanarak bölütlenmeye çalışılmış ve $\% 95$ gibi bir başarı elde edilmiştir [22].

Koldaki kırık tespiti başarısını artırmak amacıyla AC-GAN (Auxiliary Classifier Generative Adversarial Networks) derin ağlarının da uygulandığı yayınlar vardır. Bu konuya örnek olarak verilebilecek bir çalışmada araştırmacılar, bu algoritma tabanlı yöntemlerinin \%91,2 başarısı ile çalışmalarının ortopedistlere yardımcı olabileceklerini savunmuşlardır [23].

İnsanların uzun kemiklerindeki kırkların tespitinde bölüt ve kontur histogramlarının kullanıldığı bir çalışmada, sınıflandırma görevi için YSA kullanıldığı gözlemlenmiştir [24].

Ön-arka plan pelvis görüntülerinde, femur boyun kırığı tespiti için genetik algoritma ile parametre en iyilemesi yapılan CNN ağı, \%83 duyarlılık oranı ile başarılı bir çıktı üretmiştir. Farklı boyuttaki veriler ile eğitim 
işleminin tekrarlanması sonucunda ise küçük boyuttaki verilerle yüksek başarılar elde edilebileceği söz konusu çalışmada vurgulanmıştır [25].

İskelet-kas doku bölütlemesindeki CNN performansı ile kemik yaşı kestirimi gibi araştırmalar da rastlanabilecek yayın konularındandır [26-27].

İnsan bileğini kırık ve sağlam olacak şekilde iki sınıfa ayıran bir çalışmada; yazarlar 695'i kırık, 694'ü sağlam olmak üzere toplamda 1389 görüntü ile çalışmışlardır. InceptionV3 mimarisiyle \%95,4'lük başarı elde eden bu çalışma, öğrenme aktarımı (transfer learning) yönteminin medikal görüntülerde başarılı sonuçlar verdiğini göstermiştir [28].

İnsanda femur kırıklarını normal ve atipik olmak üzere iki sınıfa ayıran bir çalışmada ise, 397'si atipik, 399'u normal femur kırığından oluşan veri kümesiyle yine önceden eğitilmiş derin ağlar test edilmiştir. VGG-19, ResNet50 ve InceptionV3 mimarilerinden sirasıyla $\% 82,7, \% 89,4$ ve $\% 90,5$ başarı oranları elde edilmiştir. Araştırmacıların önerdikleri metot ile bu oranlar sırasıyla \%92,2 \%93,4 ve \%94,4 oranlarına kadar çıkarılmıştır [29].

\section{Veri Seti}

Derin öğrenme algoritmalarının eğitim işlemi için fazlaca veriye ihtiyaç duyulur ve verilerin niteliği başarılı bir çalışmanın temelini oluşturur [30]. Bu temelin sağlam atılabilmesi adına veri setinin oluşturulma aşamasında, alanında uzman veteriner ortopedistimizle birlikte çalışılmış, çalışılmaya da devam edilmektedir.

Çalışma kapsamında öncelikli olarak köpeklerdeki uzun kemiklerin sınıflandırılması hedeflenmiştir. Bu hedefin Ankara Büyükşsehir Belediyesi Sokak Hayvanları Geçici Bakım Evi’nden alınan, köpeklere ait röntgenleri içeren geniş kapsamlı bir veri seti ile gerçekleştirilmesi planlanmıştır.

Röntgen görüntülerinin çoğu Fujifilm markasının CR-IR-392 modeline ait görüntüleme cihazı sayesinde çekilmiş, FVS-1000 adındaki bir arayüz programı vasıtasıyla gönderilen lazer ışınının anlamlı görüntülere dönüştürülmesi sağlanmıştır. FVS-1000 programında incelenebilen görüntüler kırpılarak .png uzantılı resimler haline getirilmiştir. Bu şekilde şu ana dek 2439 adet görüntü incelenmiştir. İncelenen görüntülerden 669 tanesi femur, 263 tanesi humerus, 283 tanesi radius-ulna ve kalan 604 tanesi de tibia olacak şekilde toplamda 1819 adet görüntü, köpeklerdeki uzun kemiğin cinsine göre dört farklı sınıfa ayrılmıştır. 620 görüntü ise, alan dışı ya da görüntüleme esnasındaki yapılan hatalarla kaydedilen görüntüler olup veri setine dahil edilmemiştir. Veri setinin daha iyi anlaşılması adına veri setine ait detaylar Tablo 1'de verilirken, köpeklerdeki uzun kemikleri belirten bir görsel ise Şekil 1'de sunulmuştur. Şekil 1'de gösterilen ve uzun kemik çeşitlerinden biri olan fibula, aksesuar kemik olup vücut yükünü taşımada etkin rol oynamadığı için bu çalışmada fibula adını taşıyan bir sınıf oluşturulmamıştır.

Şekil 2'de ise örnek olarak veri setindeki her bir uzun kemiğe ait X-Ray görüntüsüne yer verilmiştir.

Tablo 1. Veri Seti

\begin{tabular}{|c|c|}
\hline Kemik Adı & Görüntü Sayısı \\
\hline Femur & 669 \\
\hline Humerus & 263 \\
\hline Radius-Ulna & 283 \\
\hline Tibia & 604 \\
\hline
\end{tabular}

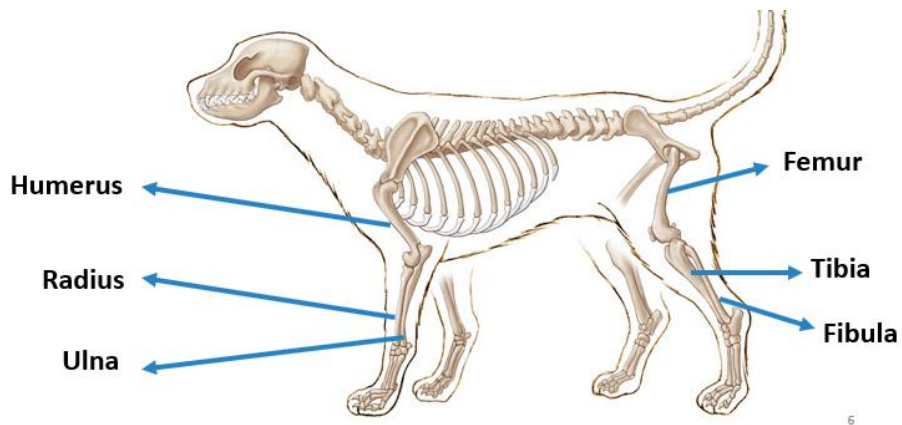

Şekil 1. Köpeklerde uzun kemikler [31]. 


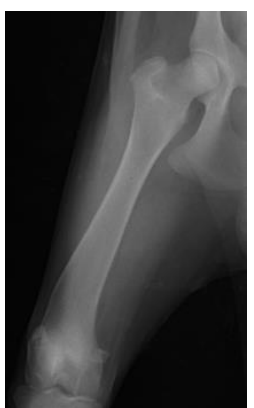

(a)

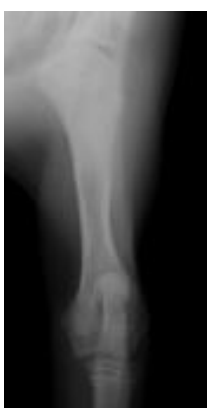

(b)

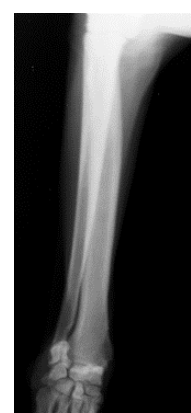

(c)

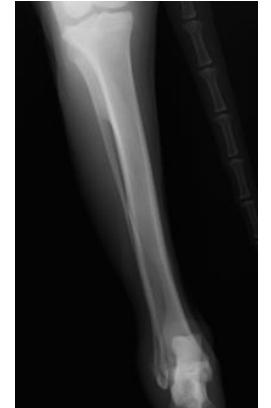

(d)

Şekil 2. Veri setinde yer alan uzun kemik çeşitlerine birer örnek.

\section{Materyal ve Metot}

Sol baştan; a) femur, b) humerus, c) raius-ulna ve d) tibia.

Bu çalışma da görüntü işlemedeki başarısı nedeniyle CNN algoritması kullanılmıştır [32]. Algoritmada eğitim ve test kümeleri veri setinden rastgele seçilmiş olup oranları sırasıyla \%80 ile \%20 olarak belirlenmiştir. Veri setinde farklı sınıfların farklı görüntü sayılarına sahip olması sebebiyle, her sınıftan yine rasgele seçilen 211 'er görüntü modele girdi olarak verilmiştir. Girdi olarak verilen tüm MR görüntülerinin boyutlar1 227x227x3 pikseldir. Algoritmada yığın boyutu 32 olarak seçilmiştir.

Ham veriler CNN modeline uygulanarak görüntüdeki öznitelikler elde edilmiş, ardından çok sınıflı Destek Vektör Makineleri ile sınıflandırılmıştır.

\subsection{Evrişimsel Sinir Ă̆ları}

2012 yılında G. Hinton ve Alex Krizhevsky, günümüzde "AlexNet” olarak bilinen derin ağ yapısını ortaya atmış, sekiz katmanlı bir evrişimsel sinir ağı eğitmiştir [33]. Bu ağ yapısının getirdiği başarının ardından CNN yapısı özellikle görüntü işlemede en yaygın kullanılan derin ağ çeşitlerinden biri olmuştur.

Basit bir CNN modeli aşağıdaki katmanlardan oluşur.

4.1.1. Evrişim Katmanı (Konvolüsyon Katmanı): Yapıya uygun olarak belirlenmiş bir filtrenin, giriş görüntüsünün pikselleri üzerinde teker teker kaydırılması işlemidir. Kaydırma sırasında filtredeki değerler görüntünün orijinal piksel değerleri ile çarpılarak toplanır ve tek değer halinde yazılır. Bu işlem, tüm girdi görüntüsü boyunca hesaplanır. Yapının ilk katmanı olan evrişim katmanı; görüntüdeki kenar, baloncuk ve eğri gibi düşük seviyeli öznitelikleri tespit eder.

4.1.2. Havuzlama (Ortaklama): Bu katmanda genellikle maksimum havuzlama (max pooling) yöntemi kullanılır. Bu katman sayesinde girdi boyutları küçültülerek hesaplama maliyeti azaltılır.

4.1.3. Tam Bağlaşımlı Katman: Bu katman, son katman olarak bilinir ve girdi, sınıf sayısı boyutunda bir vektör haline getirilir. Bu katmanda konumlandırılmış bir softmax fonksiyonu ile çıkarılan yüksek seviyeli öznitelikler bir sınıf ile bağdaştırılır.

Evrişim ve havuzlama katmanları, ağ içerisinde istenildiği kadar kullanılabilir. Her bir katman sonrası daha yüksek öznitelik uzayına geçilir ve en nihayetinde elde edilen özniteliklerin sınıflandırılması yapılır. Burada kaç katman kullanılacağı, filtrenin hangi boyutta seçileceği, evrişim aşamasında filtrenin kaç adımda bir kayacağı (stride size) gibi parametrelerin seçimi kullanılan veri setine bağlı olarak değişmektedir.

\subsection{Evrişimsel Sinir A ğları Mimarileri}

Son yıllarda birbirinden farklı pek çok CNN mimarisinin kullanımına tanık olunmuştur. Bu mimarilerin birbirlerinden temel farkı, derinlikleri ve beraberinde getirdiği parametre sayılarıdır [34].

Bu çalışmada, AlexNet, GoogleNet ve VGG-19 mimarileri incelenmiştir.

4.2.1. AlexNet: 2012 yılında gerçekleştirilen ImageNet yarışmasını kazanan bu model, derin öğrenme için bir dönüm noktası olmuştur. Model, 5'i evrişim ve 3'ü tam bağlaşımlı olmak üzere toplamda 8 katmandan oluşmaktadır. Mimaride kullanılan filtreler 11x11 boyutlarında seçilmiştir. Ayrıca model, Rectified Linear Units (ReLUs) fonksiyonunu aktivasyon fonksiyonu olarak kullanan ilk derin ağ modelidir. Model, yaklaşık 60 milyon parametreye sahiptir [33]. Mimari yapı, Şekil 3'te gösterilmiştir. 


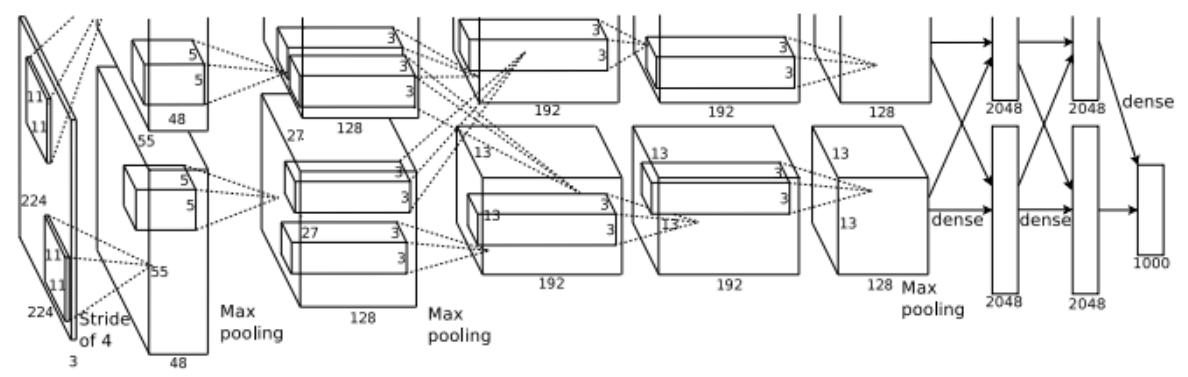

Şekil 3. AlexNet Mimarisi [33].

4.2.2. GoogLeNet: 2014 yılında literatüre kazandırılan bu model, o yılki ImageNet yarışmasını kazanmıştır. Toplamda 22 katmandan oluşan model, AlexNet'e oranla çok daha derin bir yapıya sahiptir. Bu modelde, paralel modüller kullanılarak ezberleme (overfitting) probleminin önüne geçilmeye çalışılmıştır [35]. GoogLeNet ağ Şekil 4'te verilmiştir.

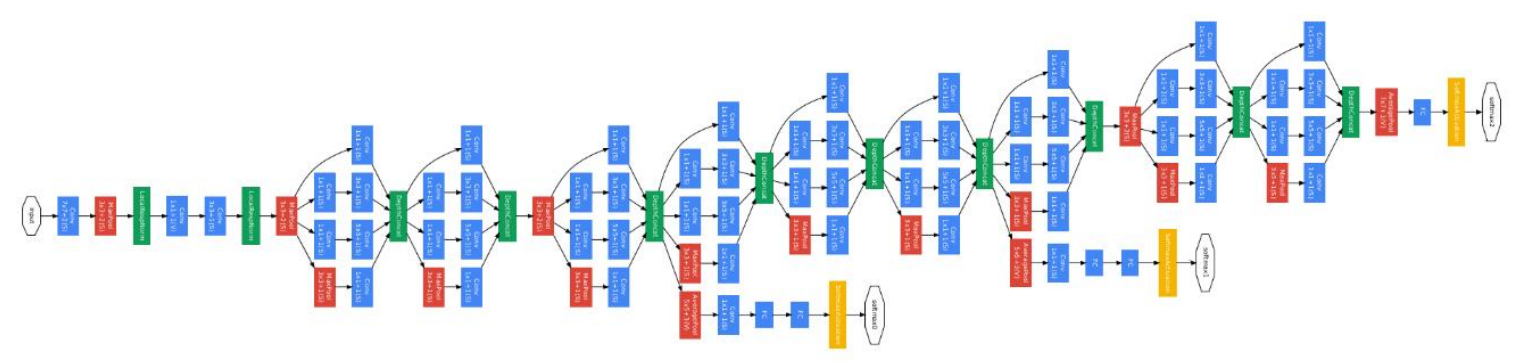

Şekil 4. GoogLeNet Mimarisi [35].

4.2.3. VGG-19: Ağ 16'sı evrişim, 3'ü tam bağlaşımlı olmak üzere toplamda 19 katmandan oluşur. Bu mimaride kullanılan filtreler $3 \times 3$ boyutundadır. VGG-19 modeli yaklaşık 144 milyon parametre içermektedir [36]. Mimari yap1, Şekil 5 'te verilmiştir.

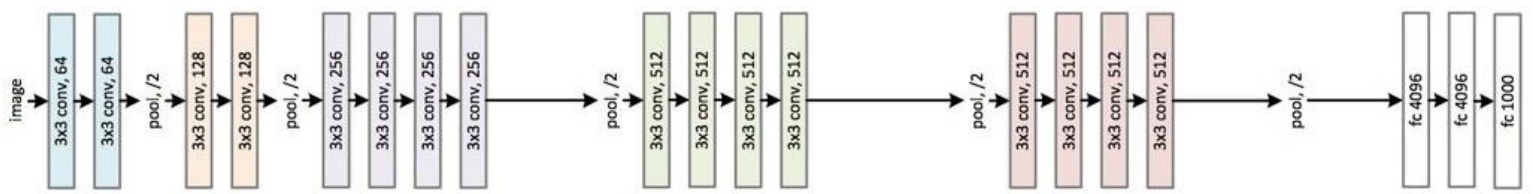

Şekil 5. VGG-19 Mimarisi [37].

\subsection{Destek Vektör Makineleri}

Bu makine öğrenme algoritmasının temeli, iki sınıf arasına bir hiper düzlem çizerek verileri ayırma işlemine dayanmaktadır [38]. Bu yöntem, daha çok iki sınıftan oluşan verileri sınıflandırmada kullanılmaktadır; ancak çok sınıfa ait problemler için de farklı yaklaşımları bulunmaktadır. Bu yaklaşımlardan en çok kullanılan bire bir yaklaşıma göre, tüm sınıflar önce ikili gruplar halinde SVM ile eğitilmektedir. Ardından tüm SVM'ler birbiriyle kıyaslanarak hangi sınıf için en güvenilir sonucun çıktığına bakılmakta ve veri bu sınıfa atanmaktadır [39].

SVM'nin literatürde en başarılı metotlardan biri olarak görülmesi, bu çalışmanın sınıflandırıcısı için tercih sebebi olmuştur [40-42]. 


\section{Tartışma ve Deneysel Sonuçlar}

Görüntüleri etiketleme işleminin ardından, uygun derin ağ mimarisini seçmek amacıyla en popüler üç mimari ile öğrenme aktarımı gerçekleştirilmiş ve sonuçlar Tablo 2'de özetlenmiștir.

Öğrenme aktarımı, derin öğrenmede en sık başvurulan yöntemdir. Çünkü derin öğrenme modelleri, eğitilmek için çok fazla veri ve bununla beraber de performansı yüksek bir donanım ihtiyacı duyar. Dolayısıyla önceden eğitilmiş bir ağı kullanmak, ağı baştan eğitmeye oranla daha kısa zamanda iyi sonuçların elde edilebileceği bir yöntem olarak karşımıza çıkar [43]. Bu çalışmada da üç farklı eğitilmiş ağ ile sınıflandırma performansı karşılaştırılmak istenmiştir. Sonuçlara göre, en iyi sınıflandırma başarısının yüzde 82, 82' lik başarıyla AlexNet ile yakalandığı görülmektedir. Buna karşın; GoogLeNet ile VGG-19 mimarilerine ait başarıların da AlexNet'den çok farklı olmadığı anlaşılmaktadır. Buradan hareketle öğrenme aktarımı yönteminin, literatürdeki benzer çalışmalar gibi, bu çalıșmada kullanılan veri seti için de etkili olduğunu söylenebilir [44]. Çünkü bu üç mimari de öncesinde büyük fotoğraf boyutlarında eğitilmiş ve farklı sınıflar için modelini genelleştirmeyi başarabilmiştir. Ayrıca Tablo 2'deki değerler kıyaslandığında, her ne kadar sonuçlar birbirine yakın olsa da öğrenme modelindeki katman sayısının artırılması sınıflandırma performansını olumsuz etkilemiştir. Bunun sebebi olarak, bir noktadan sonra ağın girdi tarafindan gelen öznitelikleri tekrar kullanamayarak ağın öğrenme problemi ile karşı karşıya gelmesi şeklinde yorumlanabilir [45]. Ayrıca insandaki uzun kemiklerin sınıflandırılması üzerine yapılan benzer başka bir çalışma için 6 katmanlı bir CNN modeli ile yüksek başarılar elde edildiği tespit edilmiştir [46].

Sınıflandırma performansını daha iyi irdelemek adına, üç model için de oluşturulan karmaşıklık matrislerine Tablo 3’te yer verilmiştir. Bu tabloya göre, femur ve tibia sınıflarına ait görüntülerinin daha belirgin özniteliklere sahip olması sebebiyle daha başarılı bir şekilde sınıflandırıldığı ortaya çıkmaktadır.

Tablo 2. A ğ Mimarilerine Göre Sinıflandırma Başarıları

\begin{tabular}{|c|c|}
\hline Mimari Yapı & Sinıflandırma Başarısı (\%) \\
\hline AlexNet & 82,82 \\
\hline GoogLeNet & 80,45 \\
\hline VGG-19 & 81,75 \\
\hline
\end{tabular}

Tablo 3. Ağ Mimarilerine Göre Oluşturulan Karmaşıklık Matrisleri

\begin{tabular}{|c|c|c|c|c|c|}
\hline \multirow{2}{*}{ Mimari Yapı } & \multicolumn{4}{|c|}{ Karmaşıklık Matrisi } & $\begin{array}{c}\text { Belirlilik } \\
(\%)\end{array}$ \\
\hline \multirow{3}{*}{ AlexNet } & 188 & 7 & 6 & 10 & 89,09 \\
\cline { 2 - 6 } & 26 & 167 & 10 & 8 & 79,14 \\
\cline { 2 - 6 } & 3 & 5 & 164 & 39 & 77,72 \\
\cline { 2 - 6 } & 5 & 3 & 23 & 180 & 85,3 \\
\hline \multirow{3}{*}{ Duyarlılık (\%) } & 84,68 & 91,75 & 80,78 & 75,94 & 83,28 \\
\hline \multirow{3}{*}{ GoogLeNet } & 196 & 5 & 2 & 8 & 92,89 \\
\cline { 2 - 6 } & 36 & 152 & 2 & 21 & 72,03 \\
\cline { 2 - 6 } & 6 & 5 & 166 & 34 & 78,67 \\
\cline { 2 - 6 } & 19 & 10 & 17 & 165 & 78,2 \\
\hline Duyarlılık (\%) & 76,26 & 88,37 & 88,77 & 72,36 & 81,44 \\
\hline \multirow{3}{*}{ VGG-19,4 } & 184 & 11 & 4 & 12 & 87,2 \\
\cline { 2 - 6 } & 42 & 152 & 10 & 7 & 72,03 \\
\cline { 2 - 6 } & 7 & 4 & 174 & 26 & 82,46 \\
\cline { 2 - 6 } & 8 & 4 & 19 & 180 & 85,3 \\
\hline Duyarlılık (\%) & 76,34 & 88,88 & 84,05 & 80 & 78,72 \\
\hline
\end{tabular}

Daha yüksek başarılar elde etmek; ağ yapılarının optimize edilmesi ve veri setinin çoğaltılması ile mümkündür [47]. Bu nedenle, kümülatif olarak güncellenen veri seti sayesinde gelecek çalışmalar adına daha çok veri ile performans iyileştirilmesi söz konusu olabilir. 


\section{Sonuç}

Çalışmada, üç farklı eğitilmiş ağ ile sınıflandırma performansı ölçülmüş ve en iyi başarının AlexNet ile elde edildiği gözlenmiştir. Üç mimariye de ait sınıflandırma başarıya bakarak, öğrenme aktarımı yönteminin, çalışmada kullanılan veri seti için uygun olduğunu söylenebilir.

$\mathrm{Bu}$ çalışmadaki amaç, bahsedildiği üzere köpeklerdeki uzun kemikleri sınıflandırmaktır. Kemiklerin sınıflandırılmasının ardından, kemiklerdeki kırığın varlığının saptanması ve var olması durumunda da kırı̆̆ın cinsine göre sınıflandırılması ise gelecek çalışmalar arasında yer almaktadır. Dolayısıyla öncelikli olarak bu çalışmadaki sınıflandırma başarısının yükseltilerek, kırıkların tespit edilmesi daha güvenilir sonuçlar ortaya çıkaracaktır.

\section{Teşekkür}

Çalışmamıza önemli katkıda bulunan ve bulunmaya devam eden Ankara Büyükşehir Belediyesi Sokak Hayvanları Geçici Bakım Evi çalışanlarına sonsuz teşekkürlerimizi sunarız.

\section{Kaynaklar}

[1] A. Şeker, B. Diri, H. Hüseyin Balık, "Derin Öğrenme Yöntemleri ve Uygulamaları Hakkında Bir İnceleme," Gazi Mühendislik Bilimleri Dergisi, vol. 3, pp. 47-64, 2017.

[2] A. Prasoon, K. Petersen, C. Igel, F. Lauze, E. Dam, M. Nielsen, "Deep Feature Learning for Knee Cartilage Segmentation Using a Triplanar Convolutional Neural Network," MICCAI, pp. 246-253, 2013.

[3] Sergio, P., Adriano, P., Carlos, A, "Brain Tumor Segmentation using Convolutional Neural Networks in MRI Images" IEEE Transactions on Medical Imaging, pp. 1240-1251, 2016.

[4] G. Urban, M. Bendszus, F. A. Hamprecht, J. Kleesiek, "Multi-modal Brain Tumor Segmentation using Deep Convolutional Neural Networks," MICCAI BraTS Challenge Proceedings, pp. 31-35, 2014.

[5] Adams M, Chen W, Holcdorf D, McCusker M W, Howe P D, Gaillard F., "Computer vs human: deep learning versus perceptual training for the detection of neck of femur fractures," J Med Imaging Radiat Oncol; vol.63, pp. 27-32, 2019.

[6] Brett A, Miller C G, Hayes C W, Krasnow J, Ozanian T, Abrams K, Block J E, van Kuijk C., "Development of a clinical workflow tool to enhance the detection of vertebral fractures: accuracy and precision evaluation," Spine, vol. 34, pp. $2437-$ 2443, 2009.

[7] Chung S W, Han S S, Lee J W, Oh K S, Kim N R, Yoon J P, Kim J Y, Moon S H, Kwon J, Lee H J, Noh Y M, Kim Y., "Automated detection and classification of the proximal humerus fracture by using deep learning algorithm," Acta Orthop, vol. 89, pp. 468-473, 2018.

[8] Szegedy C, Vanhoucke V, Loffe S., "Rethinking the Inception Architecture for Computer Vision," IEEE Conference on Computer Vision and Pattern Recognition (CVPR), Las Vegas, pp. 2818-2826, 2016.

[9] Lindsey R, Daluiski A, Chopra S, Lachapelle A, Mozer M, Sicular S, Hanel D, Gardner M, Gupta A, Hotchkiss R, Potter H., "Deep neural network improves fracture detection by clinicians," Proc Natl Acad Sci USA, vol. 115 pp. 11591-11596, 2018.

[10] Najafabadi, M.M., Villanustre, F., Khoshgoftaar, T.M. et al. Deep learning applications and challenges in big data analytics. Journal of Big Data 2, 1, 2015.

[11] J. Seetha, S.S. Raja, "Brain Tumor Classification Using Convolutional Neural Networks," Biomed Pharmacol J, vol. 11, 2018.

[12] Zbigniew A. Starosolski, J. Herman Kan, and Ananth Annapragada "CNN-based detection of distal tibial fractures in radiographic images in the setting of open growth plates", Proc. SPIE 11314, Medical Imaging 2020: Computer-Aided Diagnosis, 2020.

[13] YÖK Ulusal Tez Merkezi, “https://tez.yok.gov.tr/UlusalTezMerkezi/tezSorguSonucYeni.jsp,” erişim: 15.45, 11.10.2020.

[14] O. Yıldız, "Derin öğrenme yöntemleriyle dermoskopi görüntülerinden melanom tespiti: Kapsamlı bir çalışma," Gazi Üniversitesi Mühendislik Mimarlık Fakültesi Dergisi, vol. 34, pp. 2241-2260, 2019.

[15] B. Harangi, "Skin lesion classification with ensembles of deep convolutional neural networks," J Biomed Inform.vol. 86, pp. 25-32, 2018.

[16] A. Esteva, B. Kuprel, R.A. Novoa, J. Ko, S.M. Swetter, H.M. Blau, and S. Thrun, "Dermatologist-level classification of skin cancer with deep neural networks," Nature, vol. 542, 2017.

[17] M. Siar and M. Teshnehlab, "Brain Tumor Detection Using Deep Neural Network and Machine Learning Algorithm," 9th International Conference on Computer and Knowledge Engineering (ICCKE), Mashhad, Iran, pp. 363-368, 2019.

[18] S. Khawaldeh, U. Pervaiz, A. Rafiq, R. S. Alkhawaldeh, "Noninvasive Grading of Glioma Tumor Using Magnetic Resonance Imaging with Convolutional Neural Networks," Appl. Sci., vol. 8, 2018. 
[19] A. Le Berre, K. Kamagata, Y. Otsuka, et al. "Convolutional neural network-based segmentation can help in assessing the substantia nigra in neuromelanin MRI,” Neuroradiology, vol. 61, pp. 1387-1395, 2019.

[20] Couteaux V, Si-Mohamed S, Nempont O, et al. "Automatic knee meniscus tear detection and orientation classification with Mask-RCNN,” Diagn Interv Imaging, vol. 100, pp. 235-242, 2019.

[21] M. Gopalakrishnan, J. Sheng, M. Valesani, “Automated Detection of Breaks and Fractures in X-Ray Bone Images,” 2019.

[22] Johannes Kvam, Lars Erik Gangsei, Jørgen Kongsro, Anne H Schistad Solberg, "The use of deep learning to automate the segmentation of the skeleton from CT volumes of pigs," Translational Animal Science, vol. 2, pp. 324-335, 2018.

[23] C. Chin, Y. Lin and Y. Liu, "Various Types Fracture Labeling in Bone Radiographs Using Modified AC-GAN," 2019 International Conference on Technologies and Applications of Artificial Intelligence (TAAI), Kaohsiung, Taiwan, pp. 16, 2019.

[24] A. Yi Yang, 1. Cheng, "Long-Bone Fracture Detection Using Artificial Neural Networks Based on Contour Features of Xray Images," 2019.

[25] S. Beyaz, Salih, K. Açıcı, E. Sümer, "Derin Öğrenme ve Genetik Algoritma Yaklaşımları Kullanılarak X-Ray Görüntülerinde Femur Boyun Kırı̆ğ Tespiti,” Uluslararası Sağlıkta Yapay Zeka Kongresi, İzmir, Türkiye, 2020.

[26] F. Liu, Z. Zhou, H. Jang, A. Samsonov, G. Zhao, R. Kijowski, "Deep convolutional neural network and 3D deformable approach for tissue segmentation in musculoskeletal magnetic resonance imaging," Magnetic Resonance in Medicine, 2017.

[27] Wang et al., "Skeletal Maturity Recognition Using a Fully Automated System with Convolutional Neural Networks," IEEE Access, vol. 6, pp. 29979-29993, 2018.

[28] D. H Kim, T. MacKinnon, "Artificial intelligence in fracture detection: Transfer learning from deep convolutional neural networks," Clin. Radiol., vol. 73, pp. 439-445, 2018.

[29] Y. Chen, "Classification of Atypical Femur Fracture with Deep Neural Networks," KTH University: Stockholm Sweden, 2019.

[30] Dargan, S., Kumar, M., Ayyagari, M.R. et al. "A Survey of Deep Learning and Its Applications: A New Paradigm to Machine Learning,” Arch Computat Methods Eng., vol. 27, pp. 1071-1092, 2020.

[31] Stock Medical and Veterinary Illustrations, "drawing of $\operatorname{dog}$ skeletal system," http://yesko.com/medical_illustrations/stock-illustration-dog-anatomy-01.htm, erişim: 19.01, 19.10.2020.

[32] Yamashita, R., Nishio, M., Do, R.K.G. et al. Convolutional neural networks: an overview and application in radiology. Insights Imaging, vol. 9, pp. 611-629, 2018.

[33] A. Krizhevsky, I. Sutskever, G. Hinton, "ImageNet classification with deep convolutional neural networks," NIPS'2012, 2012.

[34] Ö. İnik, E. Ülker, "Derin Öğrenme ve Görüntü Analizinde Kullanılan Derin Öğrenme Modelleri," Gaziosmanpaşa Bilimsel Araştırma Dergisi vol. 6, pp. 85-104, 2017.

[35] C. Szegedy et al., "Going deeper with convolutions," 2015 IEEE Conference on Computer Vision and Pattern Recognition (CVPR), Boston, pp. 1-9, 2015.

[36] K. Simonyan, A. Zisserman, "Very Deep Convolutional Networks for Large-Scale Image Recognition,” conference paper at ICLR 2015.

[37] Ahmed Abdelbaki, "P-CNN features for Action Recognition," Computer Vision Lab SS16, 2016.

[38] Cortes, C., and Vapnik, V. “Support-vector networks. Machine Learning,” vol. 20, pp. 273-297, 1995.

[39] Çok sınıflı DVM (Multiclass SVM), http://bilgisayarkavramlari.sadievrenseker.com/2008/12/01/cok-sinifli-dvmmulticlass-svm/, erişim: 19.51, 19.10.2020.

[40] A. Tekerek, "Support Vector Machine Based Spam SMS Detection,” Journal of Polytechnic, vol. 22, pp.779-784, 2019.

[41] Padmavathi Janardhanan, Heena L., and Fathima Sabika, "Effectiveness of Support Vector Machines in Medical Data mining," Journal of Communications Software and Systems, vol. 11, 2015.

[42] A. Yahiaoui, O. Er, N. Yumusak, "A new method of automatic recognition for tuberculosis disease diagnosis using support vector machines," Biomedical Research, vol. 28, 2017.

[43] L. Torrey and J. Shavlik, "Transfer Learning," Handbook of Research on Machine Learning Applications, IGI Global, 2009.

[44] N. Tajbakhsh et al., "Convolutional Neural Networks for Medical Image Analysis: Full Training or Fine Tuning," IEEE Transactions on Medical Imaging, vol. 35, 2016.

[45] S. Zagoruyko, N. Komodakis, "Wide Residual Networks," 2017.

[46] Nitesh Pradhan et al., "Classification of Human Bones Using Deep Convolutional Neural Network," IOP Conference Series: Materials Science and Engineering, 2019.

[47] C. Shorten, T.M. Khoshgoftaar, “A survey on Image Data Augmentation for Deep Learning,” J Big Data 6, 60, 2019. 